\title{
Diagramas semióticos em textos comunicacionais
}

\author{
Irene de Araújo Machado
}

\section{Resumo}

0 presente artigo discorre sobre a leitura

dos textos de comunicação como processo de aprimoramento cognitivo. Para isso, parte da hipótese da necessidade de alfabetização semiótica nas estruturas relacionais e diagramáticas que as linguagens dos meios introduziram na cultura. Propõe, assim, exercícios de leitura estrutural de textos jornalísticos em seu processo de representação. Pretende com isso examinar como os acontecimentos significam, como se tornam textos e de que instrumentos as linguagens se servem para construir argumentos que possam ser lidos na estruturalidade de sua composição.

\section{Palavras-chave}

Estrutura. Diagrama. Linguagem. Argumentação. Leitura. Visualidade.

\section{Irene de Araújo Machado | irenemac@uol.com.br}

Universidade de São Paulo - USP. Possui graduação em Letras pela Faculdade de Filosofia Letras e Ciências Humanas pela Universidade de São Paulo (1977), Mestrado em Comunicação e Semiótica pela Pontifícia Universidade Católica de São Paulo (1985) e Doutorado em Letras (Teoria Literária e Literatura Comparada) pela Universidade de São Paulo (1993). Atualmente é Professora Assistente Doutora da Escola de Comunicações e Artes da Universidade de São Paulo onde ministra a disciplina Semiótica da Comunicação na Cultura e orienta pesquisas de mestrado e doutorado. É Editora Científica de MATRIZes e pesquisadora do CNPq (PQII).

\section{Introdução: \\ o difícil exercício da leitura}

Em tempos de sociedade de informação, de homens e feitos midiáticos, não é difícil reconhecer que 0 discurso sobre 0 mundo se tornou enunciação dos meios tecnológicos. Tampouco existe algum mistério na definição que atribui aos chamados textos da comunicação mediada a experimentação de códigos criadores de linguagens técnicas que, ao se constituírem para além da expressão verbal, enunciam-se como exemplares inconfundíveis da cultura visual. 0 difícil, neste caso, é operar a leitura argumentativa dos textos produzidos pelo processo de transcodificação e configurados por estruturas de diferentes linguagens. Ainda que a transmissão de informação seja objetivo imediato, os procedimentos composicionais dos textos estão comprometidos com um processo maior de trânsito de ideias.

Sabemos que o grande feito da cultura letrada foi a criação do homem leitor, aquele que aprende 0 alfabeto para ler textos escritos onde quer que eles se manifestem. 0 aprendizado da escrita e da 
leitura nunca teve como objetivo uma finalidade profissional, mas sim um aprimoramento intelectual. É possível dizer que somos alfabetizados, igualmente, para ler as linguagens formadas por códigos que excedem a grafia de palavras? Estamos capacitados para alcançar o potencial argumentativo dos textos constituídos por diferentes estruturas de linguagem da cultura de meios? Difícil afirmar com certeza, sobretudo porque o exercício pleno da linguagem, historicamente vinculado a formas de poder, de controle e de acesso aos patrimônios culturais e cognitivos, não se restringe às facilidades implementadas por meios digitais. Aqui começa 0 nosso problema.

As estruturas visuais da cultura de imagens é um campo bastante rico de reflexões nesse sentido, menos pela novidade que anuncia e mais pelas contradições das práticas de leitura que tem estimulado. Se, por um lado, a cultura de imagens surge no contracampo da cultura literária, polarizando a relação entre palavra e imagem, por outro, o exercício de leitura das imagens, grosso modo, não avançou nas singularidades dos signos visuais, sobretudo no que diz respeito aos diagramas icônicos do pensamento para a constituição de argumentos gráficos ${ }^{1}$. Enquanto a escrita da imagem compete a profissionais, a leitura da imagem é privilégio de especialistas, o que abre caminho para a disseminação de formulações simplistas, seja aquela que prega a superioridade de um sistema de signos em relação a outros - como a repetido slogan "Uma imagem vale mais do que mil palavras" -, seja a da subserviência da interpretação da imagem pela palavra. Além das contradições que propagam, tais dicotomias postulam o caráter auto-explicativo das imagens que em textos informativos não passam de evidências ilustrativas sem necessidade de um aprendizado formal.

Diríamos, inicialmente, que todo empreendimento comprometido com uma ampliação de exercícios "com" e "nas" linguagens da comunicação, representa um adentramento em esferas de controle e uma conquista de bens culturais que não deveria ser apenas privilégio de muitos, mas exercício das faculdades intelectuais em ambientes de interação. A alfabetização nas escritas contemporâneas e na leitura dos sistemas de signos deveria estar na ordem do dia dos estudos sobre a linguagem dos meios. Como já alertara, em seu tempo, o linguista Roman Jakobson (1971), "propriedade privada" é um corpo estranho e nocivo à vida da linguagem. Se cultura e linguagem se confundem, é impossível considerar as linguagens da comunicação como um bem restrito a poucos. A prática de leitura dos textos de comunicação representa 
uma possibilidade não apenas de explorar as potencialidades semióticas do conhecimento humano na cultura de meios como também sua disseminação.

0 presente artigo examina e formula uma possibilidade de leitura das estruturas diagramáticas nos textos comunicacionais como forma de alfabetização nas suas linguagens da cultura visual dos meios. Não se trata de simplesmente afirmar sua condição de veículos potenciais de transmissão de informações de um para muitos. Pelo contrário, neles identificamos processos argumentativos realizados pelas linguagens que representam formas de aprimoramentos cognitivos. Assim como os livros introduziram a necessidade de aprendizagem para a escrita e a leitura dos signos gráficoalfabéticos, os textos de comunicação, desde que se constituíram como linguagem impressa, demandam processos de alfabetização que, se já estiveram centrados nas formas tipográficas, hoje se diversificaram em códigos de ordenamentos gráfico-visuais diferenciados, sobretudo se forem consideradas as dimensões audiovisuais dos meios eletrônico-digitais. Aproximar-se dos processos de codificação e recodificação através de leitura pontual é o que se propõe nesse momento. Para isso, estrategicamente, nossa análise ficará restrita à linguagem impressa do jornalismo que tem no meio impresso o seu habitat, mas não seu medium, uma vez que é notório o diálogo com o cinema, a fotografia, a televisão, as artes, a literatura e 0 design.
Cada um a seu modo oferece instrumentos de intervenção na linguagem do jornalismo. Pretende-se com isso examinar como os acontecimentos significam, como se tornam textos e de que procedimentos as linguagens se servem para formular sua argumentação gráfica. 0 objetivo é compreender como os textos podem ser lidos em sua variedade de códigos, não apenas interpretados dentro de premissas $a$ priori estabelecidas.

Nesse sentido, a estruturalidade da linguagem informativa será o objeto primordial de análise. Desenvolvido no contexto de uma cultura visual, o jornalismo aprimorou-se como linguagem de refazer contextos, de recodificar textos e de reelaborar códigos, levando às últimas consequências a semiose das formações interpretantes da cultura.

Longe de firmar oposições e confrontos entre verbal e não-verbal, o texto de comunicação revela-se como espaço semiótico de relações estruturais configuradas por diferentes códigos não necessariamente solidários: cada um afirma o que a codificação permite. Nesse caso, experimenta-se com desenvoltura 0 trânsito entre linguagens. Quer dizer, as linguagens resultam de uma programação transcodificadora que inclui um planejamento para significar 0 que não é possível representar com os signos disponíveis. Por isso, aquilo que não é possível dizer com signos verbais será experimentado em outras bases gráficas. Os textos comunicacionais 
constroem uma semiose que, como bem formulou Décio Pignatari (1968), nasce sob o signo do design. Tal é a hipótese que motivou o contexto desta investigação sobre semiosis in design. Graças à semiose, experiências de linguagem realizadas em diferentes esferas da cultura contribuem para a produção de novos processos significantes e de novas demandas de leitura. Se os textos comunicacionais pressupõem estruturas relacionais sem as quais a linguagem não se realiza, não há como descartá-las do conjunto da significação.

0 exercício aqui proposto surge de uma demanda por conhecimento estrutural da linguagem na cultura de meios. Contudo, o eixo argumentativo da análise é um rigoroso questionamento de alguns raciocínios simplistas segundo os quais os textos de comunicação são porta vozes da verdade ideologicamente constituída e, para isso, constroem artimanhas e mazelas do discurso linguístico manipulador consagrado por modos de dizer convencionados por regras igualmente consolidadas. Apoiados no compromisso ético, não apenas dos textos de comunicação como também de todos os sistemas culturais, defende-se aqui a necessidade de aprendizado de leitura das estruturas relacionais que, na história da cultura, os textos comunicacionais exercitaram sob forma de design de linguagens em suas possibilidades gráficas e diagramáticas não limitadas à palavra. Semiosis in design reporta-se a esse exercício de leitura da diversidade significante nos textos comunicacionais em prol do aprimoramento cognitivo da cultura humana. São textos de circulação social ampla que podem ser lidos na rua. Basta que a leitura seja feita com a cabeça levantada (BARTHES, 1988, p. 40).

\section{Escrita e leitura de estruturas relacionais em textos de comunicação}

Tempos de crise são um bom momento para rever conceitos que tempos de muitas certezas não permitem enxergar. A história recente tem sido cenário de adversidades e de convulsões: dos impactos ambientais à crise econômica global, como nossos jornais diários não cansam de anunciar. Convém observar, porém, que as notícias da crise não chegam até nós por meio de textos caudalosos. Formatos minimalistas de composição sob forma de manchete ou de vinheta têm sido fonte de disparos com alta dose de especulação. No jornal impresso, pequenas tiras, com planos justapostos de imagens, sintetizam ideias do cenário em pauta, cumprindo o papel de vinhetas de enunciados instantâneos.

Assim se enuncia a chamada crise estrutural dos modelos políticos, econômicos e sociais que se formaram e se consolidaram após os confrontos bélicos mundiais do século XX e da Guerra Fria subsequente. Analistas e cientistas não se cansam de anunciar a necessidade de mudanças estruturais nos empreendimentos que visam, se não resolver, pelo menos evitar o colapso. 
Se forem considerados alguns episódios da história ideológica recente, o uso eloquente do termo "estrutural" no discurso da crise tornase a incógnita de uma equação estranha, que não pode ser desconsiderada pelos estudiosos da linguagem. Sobretudo porque "estrutural" diz respeito a "estrutura", e o campo de conhecimento que fez da estrutura um objeto de estudo foi a teoria do "estruturalismo" - conjunto de formulações que marcaram 0 pensamento em ciências humanas na segunda metade do século XX.

Há, pelo menos, uma pergunta que não pode deixar de ser formulada neste momento: como o estruturalismo, considerado o principal contraponto à dialética materialista, pode definir o caráter das condutas capazes de acionar mudanças radicais em esferas decisivas da vida pública contemporânea?

Ainda que não se trate de reavivar cadáveres, é muito difícil, para os que resistiram aos ataques contra os vários estruturalismos nos anos 60, concordar com a reivindicação de mudanças estruturais na sociedade sem antes exigir precisão no uso do conceito. Nesse sentido, examinar 0 emprego do termo "estrutura" no discurso da crise atual é uma forma de discutir, criticamente, como se apresenta hoje a leitura estrutural do mundo. Afinal, conceitos têm história, e não se pode ignorar a história do estruturalismo.

As novas gerações certamente desconhecem que houve um tempo, a partir dos anos 50 do século passado, que "estrutura" era palavra maldita. Vinculada aos vários estruturalismos - particularmente à produção de intelectuais franceses - foi julgada e condenada pela carga semântica de alienação, incapaz de exprimir uma visão de mundo engajada. Deveria, pois, ser banida do universo teórico. Quais eram as ideias tão ameaçadoras das atividades teóricas que propunham compreender a estrutura das manifestações? Vale a pena compartilhar alguns pontos dessas ideias cuja história começa a ser recuperada (ver DOSSE, 2007).

Dentre as formulações desenvolvidas em diversas áreas das ciências humanas etnologia, linguística, psicanálise, sociologia, crítica literária, história - 0 estudo da "estrutura" introduziu o exercício de conjugar uma atividade investigativa e uma forma de linguagem: "0 estruturalismo é sobretudo uma nova linguagem" (COELHO, 1967, p. X). Daí a presença orientadora da língua nas teorias, despertando interesses pela busca de estrutura de linguagem nas manifestações de cultura sem distinção. Contrariando o princípio naturalista da linguagem como expressão do pensamento, desenvolveu-se 0 conceito de linguagem como esfera de articulação das ideias, conceitos e relações. Chamou-se a atenção para o signo e, ao fazê-lo, desvendou-se a convencionalidade das relações significativas que acionam 0 campo de forças da semiose: nenhum significado cabe num único termo porque a significação só se realiza como relação encadeada. Com isso, a 
noção de que existe uma relação natural entre linguagem e realidade passa a ser alvo de grandes questionamentos, sobretudo porque esta relação natural nega a convenção. Em linhas gerais, a compreensão da estrutura como possibilidade de levar adiante o projeto estruturalista de "desnaturalização dos signos como forma de combater, no plano das superestruturas, a ideologia burguesa" (idem, p. XIII), constitui-se numa grande ameaça ao logos - à palavra e à verdade única que ela pode significar. Nesse caso, a descoberta de que os signos são guiados por convenções torna-se uma premissa fundamental.

Não cabe aqui recuperar a história do estruturalismo para realizar um redimensionamento consequente de suas formulações. Se é verdade que "a fecundidade de uma ciência mede-se pelo valor operatório dos conceitos que nela se produzem" (idem, p. VII), o estruturalismo forneceu conceitos fundamentais para a leitura do mundo em suas transformações culturais. Dentre eles, o que vem em nosso socorro para que possamos pensar ações consequentes para a crise é exatamente o conceito de tempo-espaço histórico. Ainda que 0 estruturalismo tenha sido condenado por polarizar 0 conceito de história ao desqualificar a sucessividade em nome de uma operação diacrônico-sincrônica, dele herdamos a noção de neutralização do tempo como forma de compreender a estruturalidade de uma nova estrutura.
Se, por um lado, a noção de estrutura tornouse fundamento teórico do estruturalismo e o principal caminho para a descoberta das linguagens na cultura, por outro, definiu um modo de olhar o mundo: a estruturalidade de relações em níveis de abstração completamente fora da sucessividade causal. Esta seria a "história entre parênteses". É muito prematuro afirmar que tal história orienta as enunciações sobre a crise atual. Não se pode, contudo, ignorar que o jogo de forças de significado descortina relações estruturais com as quais interagimos. Se não é possível, ainda, alcançar 0 corte sincrônico da estruturalidade, podemos, minimamente, exercitar o olhar estrutural sobre o mundo. Isso posto, é necessário dizer que 0 alvo não são as ações que reivindicam mudanças estruturais da vida social, mas 0 próprio discurso da crise que se manifesta nas mensagens de textos informativos - que desenvolvem um olhar sobre o mundo por meio, evidentemente, de relações estruturais com poder argumentativo. Este é o primeiro passo de nosso exercício em que a leitura estrutural é realizada como atividade alfabetizadora.

Se, num primeiro nível, estrutura diz respeito a relações que, ao serem evocadas, projetam um nível de abstração, num outro nível, evoca padrão de conexão. Assim formulada, estrutura se torna chave conceitual para o exame do padrão de conexão que se desenha entre acontecimentos e suas representações - da história entre parênteses não fundada na causalidade, 
mas como parte de relações sistêmicas. Tal é a hipótese que fecunda o exercício de leitura estrutural dos textos jornalísticos enunciadores da crise. Para a investigação de sua pertinência e implicações, recorreremos a uma formação discursiva que tem sido reiterada em textos de caráter analítico com força argumentativa. 0 que se observa é que os argumentos gráficos não ficam contidos na palavra, à esfera verbal, mas extrapolam e encontram o continuum semiótico da cultura. A expressão gráfico-visual se desloca da esfera do logos - razão ou pensamento - e se lança para este lugar de projeção de signos em relação, a esfera do semeion. A semiose do grafismo visual dos textos comunicativos toma corpo sob forma da linguagem do design, modus operandi da escrita e da leitura relacionais em textos de comunicação, como se espera examinar nas análises que se seguem.

\section{A representação dos argumentos gráficos pelos mapas da crise}

Ainda que o estruturalismo nos anos 60 tenha sido radicalmente questionado, é inegável sua contribuição para o desenvolvimento da leitura estrutural do mundo em seus diferentes níveis de abstração. Assim, os textos jornalísticos não apenas enunciam a necessidade de mudanças estruturais como também constroem olhares e discursos estruturais sobre a crise. Basta observar que, na formulação de argumentos, não há o predomínio exclusivo dos raciocínios dedutivos e das demonstrações categóricas fundadas em asserções generalizadoras. A lógica interna do discurso jornalístico é tomada por diagramas relacionais que configuram verdadeiros mapas da crise. Não é à toa que o mapa se tornou o gênero textual por excelência deste discurso.

Contrariando o discurso da verdade única que, supostamente, é a base do texto informativo, o mapa - entendido em sua estrutura gráfico-visual de representação indicial de caminhos - abre para outras possibilidades de interpretação, de inferências e de abduções. Os mapas que são reproduzidos nos mais variados textos do jornal impresso diário nos convidam ao exercício da leitura estrutural do mundo em suas abstrações argumentativas de caráter sistêmico.

Para articular diferentes níveis de abstração, o discurso estrutural não pode ser considerado como elaboração de um código único. Há que se considerar 0 cruzamento de formações semióticas diversificadas. Logo, nosso exercício se inicia pela percepção do mapa como texto produzido como discurso linguístico e visual, sem centramento, portanto, em uma classe de signos. Do ponto de vista de sua formação semiótica, o mapa dimensiona os constituintes indiciais e simbólicos, ainda que à primeira vista seja possível reconhecer apenas uma certa configuração icônica em que o mapa redimensiona 0 território. 


\section{FRENTE FRIA}

Poucos países devem escapar do freio no crescimento em 2009, segundo o FMI

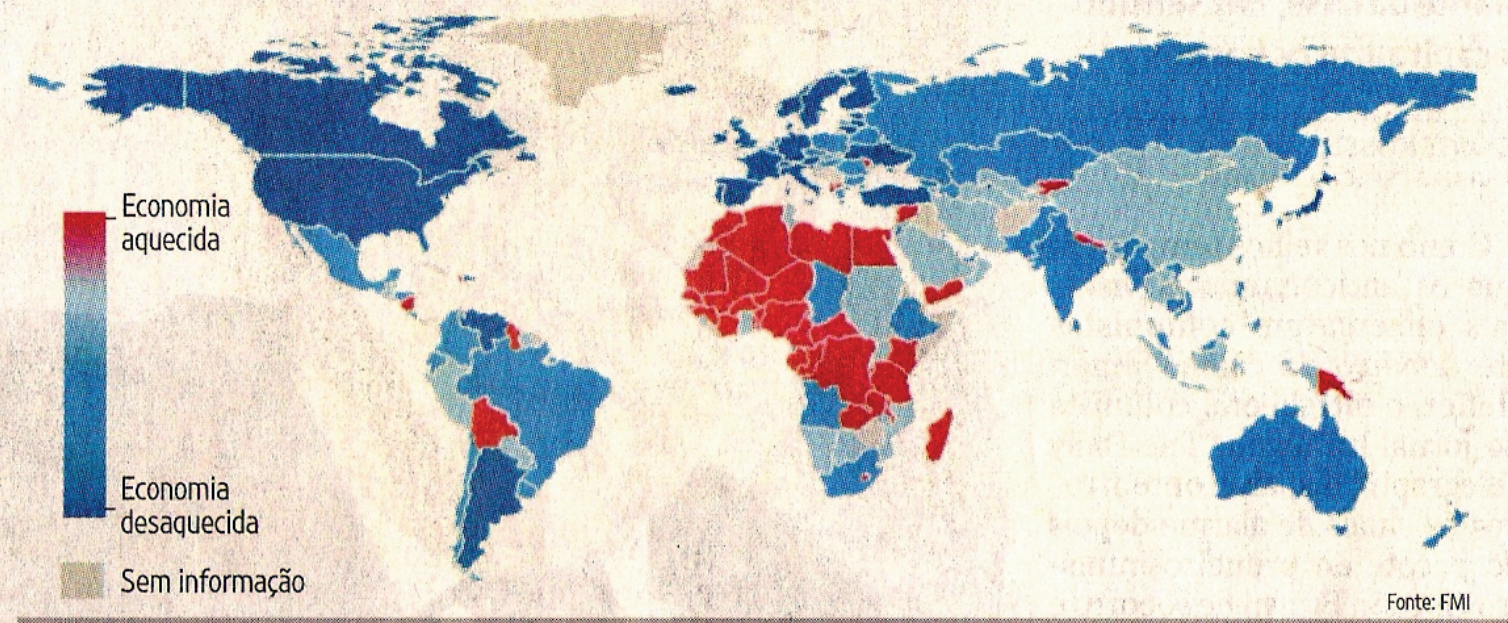

Fonte: Folha de S. Paulo, 10 de outubro de 2008, p. B9.

Figura 3 - Mapa 2

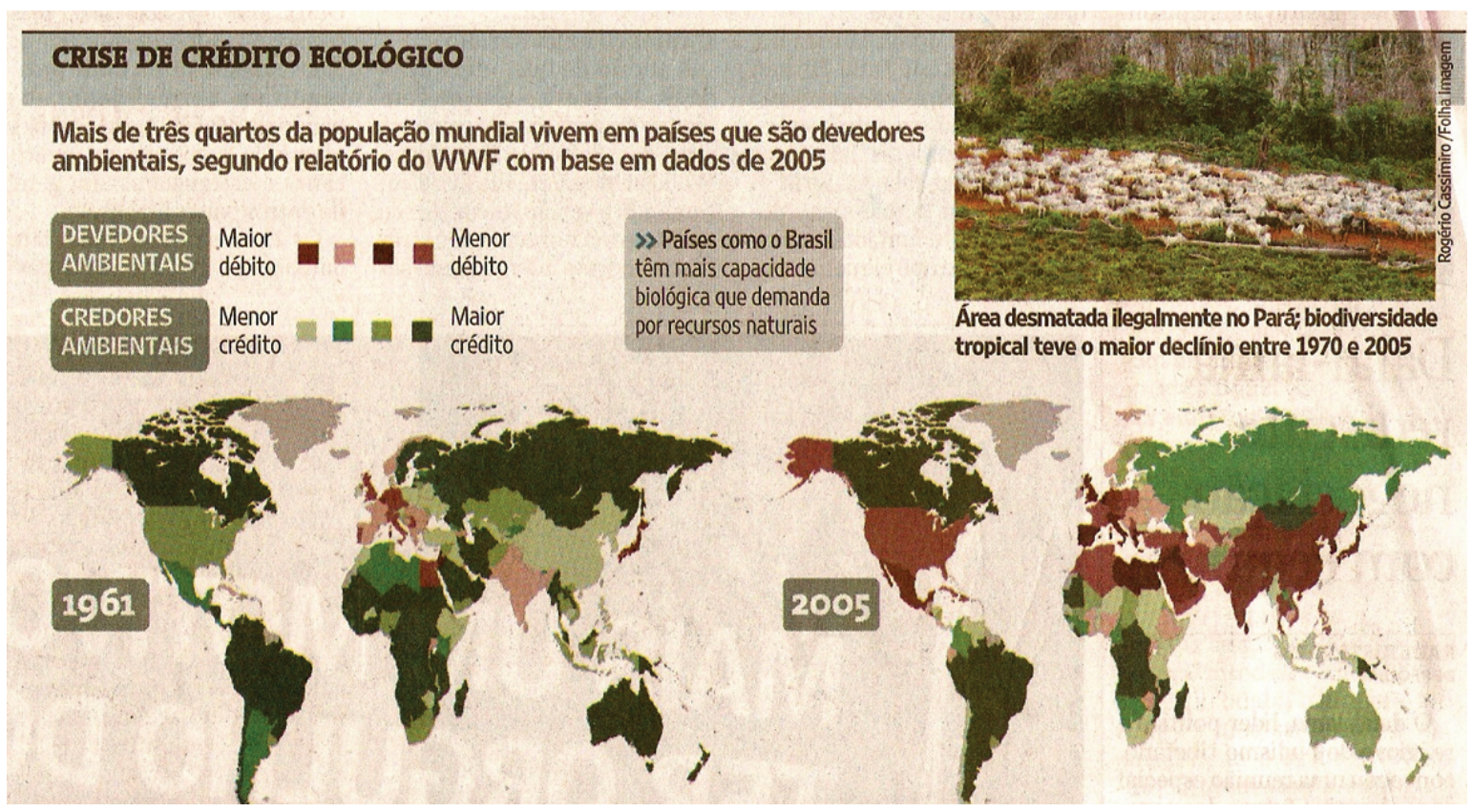

Fonte: Folha de S. Paulo, 29 de outubro de 2008, p. A16. 
Aprendemos em nossas aulas de geografia que ler o mapa não é a mesma coisa que ler pelo mapa. Enquanto que para ler o mapa é necessário reconhecer as relações icônicas que, via de regra, resultam da vinculação entre representação e referente, a leitura pelo mapa vai além do reconhecimento, chegando a uma visão estrutural com diferentes níveis de abstração. Quer dizer, por meio da representação gráfico-visual desenrolam-se interpretações, ideias e argumentos motivados pelas esferas indiciais e simbólicas. Ler "pelo" é ler "através", estabelecendo relações de diferentes ordens: a abstração de uma abstração. Para isso, vale um olhar comparativo para os mapas da crise reproduzidos nos textos jornalísticos muito mais pelo que indicia do que pelo que referencia. Ainda que eu possa ler o mesmo mapa - o mapamúndi - em cada texto, leio diferentes relações e posso chegar a diferentes abstrações de sentido. Logo, a leitura estrutural da chamada visualidade dos gráficos esconde alguns desafios perceptivos e cognitivos.

Comparando os mapas representados em diferentes noticiários e edições jornalísticas, a apreensão imediata reconhece a preocupação em apresentar dados sobre a condição climática do planeta de uma perspectiva global. Para além disso, os mapas constroem relações e, ao fazê-lo, posicionam jogos de forças à espera de interpretações. Alfred Korzibsky (apud BORGES, 1999, p. 5) foi mais longe ao afirmar que "o mapa não é 0 território". Com isso quis dizer algo muito simples, mas não tão facilmente entendido: 0 mapa não é o referente, mas um processo de representação por meio de signos que surgem de interpretações culturais - as relações interpretantes dos conhecimentos. Logo, inútil pensar o mapa como um todo único a ilustrar uma sentença. Cumpre-nos, pois, ler o jogo de forças que a construção gráfica indicia.

Afirmar que o jogo de forças é representado visualmente no mapa 1 por distinções de cores primárias, azul e vermelho, é uma foram de compreender o mecanismo dedutivo do argumento gráfico. A escala das cores e as legendas constroem variações indiciais que acrescentam ao mapa o raciocínio indutivo. Lêse, então, a possibilidade do desaquecimento da economia no mundo no contexto do aquecimento climático do planeta, o que representa, em última instância, a nossa guerra fria - e esta é uma abstração a que a leitura estrutural do mapa nos permite alcançar. Esta, porém, já não é da ordem indicial, mas simbólica, uma vez que mobiliza registros culturais e históricos. 0 mesmo encaminhamento de leitura constrói o argumento do mapa 2 , referente à emissão de gás carbônico, contudo com uma diferença: a escala de cores é reproduzida, no mapa, pela fotografia de áreas devastadas. As informações referenciais da foto entram para a composição indicial dos mapas, criando diferentes configurações entre os mapas, o de 1961 e 0 de 2005. Logo, há que se ler no mapa: os tons verdes para regiões com grandes 
reservas florestais e os tons marrons para regiões devastadas e com a terra exposta como ferida na superfície do planeta.

0 exercício de leitura estrutural realizado até aqui, ainda que com diferentes níveis de abstração, é quase uma evidência que 0 próprio convívio cultural se encarrega de estimular. Deveria, pois, constituir o alfabeto básico de leitura visual. Concentrando-se, porém, no mapa como gênero discursivo chega-se a outra abstração, formulada como pergunta: por que é o mapa-múndi o signo elementar de composição do discurso da crise? Não existiriam formas visuais talvez até mais eficientes, como barras, gráficos de porcentagens ou painéis com índices comparativos?

Convém pensar na função persuasiva da linguagem e inserir 0 argumento que defende a visão integradora do planeta não circunscrita pela noção da globalização econômica, malgrado as implicações intercontinentais. A insistência em ler os índices pelo mapa é uma premissa para a formação de uma consciência ecológica em que os homens, suas ações, suas interações com 0 ambiente e demais espécies explicitem o convívio no mundo. A representação gráfico-visual sob forma de mapa insere o homem no ecossistema de que faz parte, ainda que não todos os seres humanos tenham consciência deste fato.

0 mapa que representa um padrão de conexão no ecossistema do planeta não é, decididamente, o território e está longe de ser sua ilustração, facilitando a leitura do texto. A ideia de que existem padrões de conexão entre a diversidade de espécies vivas do planeta é um caro argumento do pensamento ecológico, graças ao qual é possível realizar uma leitura estrutural do mundo e não apenas da crise. A formação de uma consciência ecológica sistêmica se tornou a demanda fundamental de nosso tempo sem a qual as mudanças estruturais, reivindicadas no contexto da crise, não acontecem.

\section{Design de um palíndromo cartográfico}

0 mapa-múndi assim apreendido não é apenas uma representação gráfico-visual. Trata-se de um sistema semiótico formado por representações de diferentes áreas de conhecimento: das artes plásticas, da matemática, da fotografia, da geometria, da geografia, da computação gráfica e da ecologia. Com suas cores, formas, linhas, proporções, índices, porcentagens e legendas, dimensiona ecossistemas comunicacionais que selecionam e combinam articulações diferenciadas.

Seleção e combinação definem a base estrutural da linguagem segundo o linguista Roman Jakobson (1971). Ainda que a estrutura da linguagem possa configurar uma relação invariável, em funcionamento a linguagem mobiliza variáveis e variações de sentidos graças à função comunicativa, que Jakobson identificou em seis manifestações diferentes: função emotiva, referencial, conativa, fática, poética e metalinguística. À função 
metalinguística creditou a possibilidade de relações combinatórias imprevisíveis, de criação de informação nova, uma vez que a combinação envolve intervenção no código. Com isso, a linguagem se volta para si, para a estrutura da codificação. A metalinguagem se apresenta, assim, como possibilidade de recodificação.

Em que medida é possível observar processos de recodificação na utilização dos mapas do mundo nos textos de comunicação? É hora de avançar em outra direção.

Como se afirmou inicialmente, apesar da condenação ao estruturalismo, as necessidades relacionais em diferentes níveis de abstração - de uma obra artística aos ecossistemas do planeta - desenvolveram a capacidade de ver estruturalmente 0 mundo e transformar esta visão em diferentes formas de linguagem. Esta crescente demanda da produção significante me parece acolher o desenvolvimento das operações de semiose que, por intervir diretamente nos códigos, produzem design, o que levou Décio Pignatari (1968) a entender a potencialidade das linguagens da comunicação e das estruturas relacionais das mensagens como processos nascidos sob o signo do design.

Enquanto o senso comum afirma que os gráficos são facilitadores da leitura, designers da linguagem informática criam software para a interação no ecossistema em sua dinâmica planetária. Trata-se de atender à necessidade de projetar linguagens informáticas de modo a propiciar a construção de textos para abranger relações sistêmicas complexas e em grande escala.

Não é do software que se trata, mas da releitura do mundo que as estruturas relacionais do design gráfico nas linguagens da comunicação e na enunciação do discurso da crise.

No momento em que a atenção do planeta se voltou para os painéis eletrônicos das bolsas de valores, entre outubro e dezembro de 2008, telas se tornaram a selva em que monstros atacavam por meio de números, curvas, gráficos, tabelas com cores luminosas e indicadores em movimentação intensa, muito próximas do movimento dos atritos elétricos da atmosfera que os raios desenham durante tempestades. Configurou-se uma crise cuja ameaça foi anunciada por telas com dígitos, luzes, cores e diagramas projetados em tempo real para os quatro cantos do mundo, atingindo a todos com a mesma força e intensidade.

Se 0 século XXI se iniciou sob o impacto do aquecimento global, o mapa do cenário econômico assumiu outras cores: em vez do calor derretendo geleiras, estamos às voltas com frentes frias desequilibrando o aquecimento econômico alimentado pelas forças implacáveis da globalização, tal como se representa no mapa 1. As previsões não são nada otimistas e 0 que vemos é um planeta atingido por uma frente fria global. Poucos são os lugares a conservar o calor do aquecimento econômico. 
Quando vislumbrou a noção de aldeia global em que os meios de comunicação teriam papel primordial, Marshall McLuhan não pensava exatamente em economia, mas em um campo de estudo ainda em formação, cuja denominação se originou da mesma raiz grega de oikos (de lar ou terra). Definiu este campo como ambiente ou ecologia: ecologia e economia se originam da raiz oikos. Pensava que os meios de comunicação, ao promoverem trocas de informações em escala planetária, aprimorando as tecnologias eletro-eletrônicas bem como os satélites, criariam uma ecologia. Os meios funcionariam, assim, como extensões de diferentes expressões sensoriais formadoras de ambientes de comunicação numa ecologia planetária (ver MACHADO, 2009).

Porque o centro irradiador dessa ecologia é a troca de mensagens comunicacionais, e não os bens econômicos, McLuhan compreendeu a interação das diferentes linguagens - do alfabeto à tipografia, da escrita manuscrita à letra impressa - em confronto com as culturas orais, como uma galáxia que ele nomeou "galáxia de Gutenberg". A metáfora da galáxia de Gutenberg serviu de lição para outros estudiosos interessados em compreender os efeitos que os meios de comunicação e as tecnologias introduzem na cultura. Peter Lunenfeld (2003) é um desses teóricos que têm avançado nesta linha de pensamento. Suas observações levaram-no à compreensão, não dos meios, mas das operações de design que acontecem no campo das linguagens e dos códigos desenvolvidos pelos diferentes sistemas em interação na galáxia. Nesse sentido, diferentemente das galáxias agregadoras de meios, Lunenfeld entende que o presente estágio de nossa cultura desenvolve-se como "a constelação do design" (2003, p.10-15). Trata-se de uma linha de pensamento de Lunenfeld que elaborou uma formulação desafiadora, como se pode ler a seguir.

Certa vez eu vi Koolhaas ${ }^{2}$ analisar a evolução da arquitetura em relação à globalização do capital. Ele exibiu a projeção do mercado com 0 hemisfério ocidental à esquerda, Eurásia no centro e Austrália à direita. Koolhaas começou a falar das estratégias mundiais dominantes lendo, da esquerda para a direita: dólar \$, euro $€$, yen $¥$. Numa brilhante inversão das normas cartográficas, então, 0 próximo slide situava a Ásia à esquerda, a Europa no centro e os EUA à direita, criando um supergráfico de estratégias: $¥ \mathbf{€} \mathbf{\$}$, ou, como Koolhass chamou, o YES global (LUNENFELD, 2003, p. 13).

0 gráfico apresentado por Koolhaas não consta no livro de onde esta citação foi retirada; contudo, encontra-se disponível na fonte web da legenda, de onde recolhemos para reprodução. 


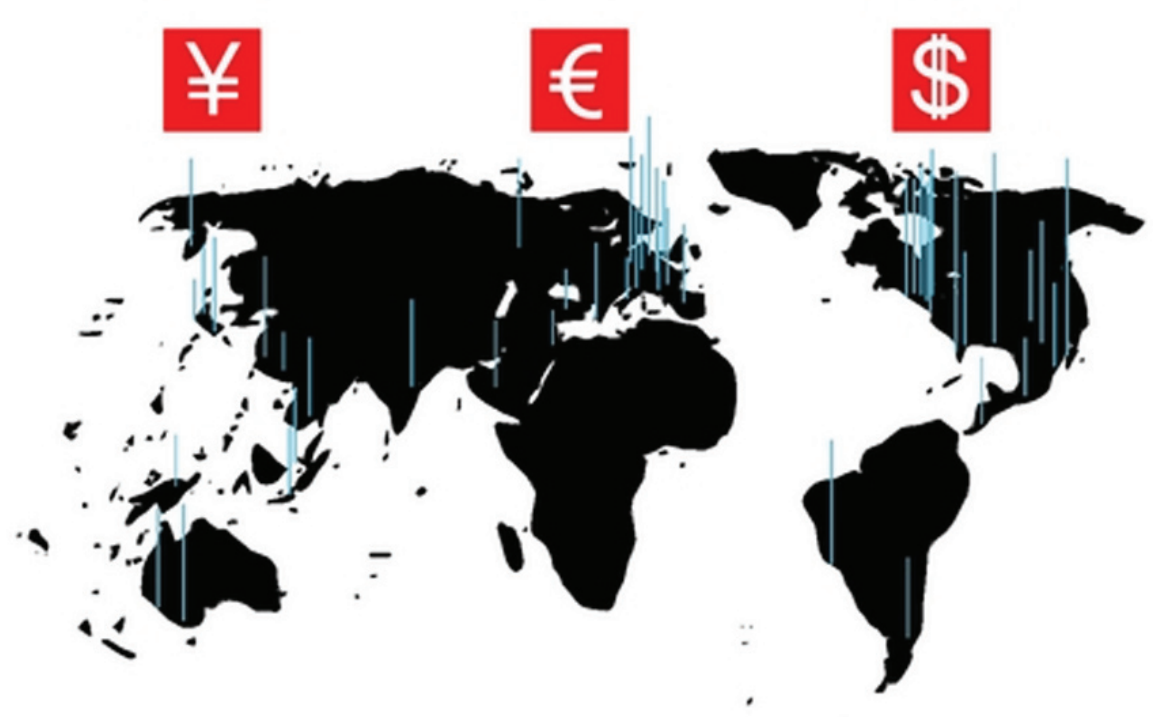

Fonte: Rem Koolhaas, Dilemmas in the Evolution of the Cities, 2007 Disponivel em: <josegenao.wordpress.com/2007/06/>.

0 gráfico de Koolhaas na verdade não é exatamente o mapa-múndi, mas um interpretante das relações econômicas sintetizadas na palavra $¥ € \mathbb{\$}$, que, por seu turno, resulta de uma intervenção metalinguística no mapa, isto é, realinhamento dos continentes segundo as variações dos mercados e de suas moedas. Há, portanto, um argumento gráfico muito preciso na representação de Koolhaas: mudança radical no jogo de forças da economia globalizada e do surgimento de novos mercados desencadeado pelo aquecimento de economias emergentes.

Graças à operação de design, o gráfico apresenta um interpretante do signo, ou seja, uma estrutura em que a interpretação é reelaborada em confronto com a experiência. Para Décio Pignatari (1968, p. 30), "o interpretante, assim, não é uma coisa, mas antes o processo relacional pelo qual os signos são absorvidos, utilizados e criados".

Num primeiro momento, é possível dizer que a base gráfica formadora do argumento foi o mapamúndi segundo uma percepção de movimento em economias emergentes no contexto global, não da globalização econômica, mas no globo terrestre. Contudo, não há aqui uma estrutura de cor e legenda. Tal como as pressões atmosféricas, as pressões dos agentes econômicos são mobilizadoras e interventoras. Assim, quando Koolhaas inverte a cartografia, ele opera uma 
modelização das relações ecológicas em função das transformações econômicas. Quando, porém, desenha o signo gráfico da moeda de cada região no contexto desta cartografia, surge um signo novo: $0 ¥ € \$$ global. Este é um signo novo porque sua base gráfica não são as letras do alfabeto nem ocidental, nem oriental - mas as cifras das moedas respectivas. Paradoxalmente, a leitura que nossa visão realiza não leva em conta os signos gráficos, mas a semiose acústica de outra palavra, o termo yes da língua inglesa. Assim, a carta do globo terrestre é renomeada com os signos gráficos da semiose econômica. Ainda que se possa ler o signo $¥ € \mathbf{€}$ como a palavra yes, no contexto do gráfico desenhado pelo jogo de forças ecológico-econômico trata-se de uma controvérsia: um contexto de crise. Algo muito próprio da globalização que firma a positividade a partir de movimentos subterrâneos de negação.

Se este fosse um artigo de economia, certamente eu iria encaminhar ideias econômicas do exemplo apresentado por Koolhaas. 0 viés semiótico, porém, enfatiza a controvérsia do processo de modelização semiótica do design deste signo novo resultante de classes de signos distintas, abrindo caminho para a constelação do design que Lunenfeld (2003, p. 10) entende dominar a cultura de nosso tempo de crises e de controvérsias.

Chamo de palíndromo cartográfico o texto que resulta de diferentes semioses porque, tal como no palíndromo, a composição se realiza graças ao movimento dos códigos num jogo entre mapa e cifras, alternando as direções da leitura. 0 neologismo $¥ € \$$ surge do movimento reverso do mapa, não da linearidade unidirecional da escrita alfabética (somente da esquerda para a direita). 0 modelo produzido já não é mais um mapamúndi, mas uma representação gráfico-visual de um ponto de vista sobre o mundo. Atente-se que o Japão, potência econômica cifrada pelo iene, ocupa uma pequena fração do espaço, no canto esquerdo da parte inferior do quadro, criando uma desproporção com a massa gráfica do continente europeu (euro) e americano (dólar), em linha ascendente e na diagonal.

Há que se considerar igualmente a operação sensorial e cognitiva que aqui se manifesta como gesto de leitura realizado por associações. 0

¥ € \$ global só é lido como letra do alfabeto fonético porque conhecemos as palavras a partir das quais a notação gráfica foi realizada: iene, euro, dólar. Estamos, pois, mergulhados no ambiente da cultura escrita alfabética que desenvolve códigos e sistemas notacionais para atender necessidades comunicativas e cognitivas que não cabem na interação pela linguagem verbal ordinária. Fora deste ambiente, talvez 0 $¥ €$ \$ global soe como um nonsense. Aqui não é. A semiotização do código é uma demanda do ambiente de relação em design.

Toda essa decomposição analítica da interação com o gráfico se realiza em presença do signo discreto, das cifras e das letras. Isso não acontece 
com o signo contínuo: o mapa-múndi não pode ser decomposto em unidades sem perder sua capacidade de representar o sistema do planeta. Ainda que seja resultado da modelização de outras representações, estas não projetam o mapa em fragmentos. Ele só significa in continuum: uma constelação, como queria Lunenfeld.

\section{Considerações finais}

Tanto a galáxia de Gutenberg quanto a constelação do design são reveladoras das conjugações sistêmicas não apenas dos textos como também do modo de ver o mundo e de nele conviver. As diferentes estruturas constroem diferentes mensagens. No caso da consciência ecológica apresentada nos vários textos, não se trata de verdade única nem de teleologia. Tratase de interação sistêmica expressa em leituras estruturais com diferentes níveis de abstração - tão necessárias para todo ato de conhecimento. Com isso, afirma-se a necessidade da abstração tanto para o processo de argumentação quanto da alfabetização na cultura, uma vez que nenhum sistema de signo é auto-suficiente.

A análise dos textos aqui apresentada não tem como objetivo uma focalização exaustiva de procedimentos a partir de teorias. 0 objetivo é explicitar no exercício a leitura das relações estruturais que colocam em jogo diferentes abstrações, ativando o contexto de relações, aproximações e distanciamentos na operação cognitiva que a mente põe em ação em contato com o mundo. Os acontecimentos existem, ou melhor, acontecem. A partir do momento em que eles passam a ser objeto de interpretação, eles se tornam signos de leitura que se oferecem sob forma de alguma composição e podem ser assim dimensionados por outras leituras. Tenta-se recuperar a cadeia associativa de intuições e de probabilidades que os processos sensoriais transformam em percepções. A leitura assim concebida é um gesto de raciocínio que na busca por deduções dos fatos não abandona as inferências e abduções. Em vez de ser guiada pela lógica, segue os passos nem sempre fluidos da analógica.

A leitura estrutural assim concebida define duplamente o que tentamos examinar aqui como semiosis in design. Por um lado, nomeia o processo semiótico que traduz a ação do signo em sua interação dinâmica com outros signos; por outro, qualifica a semiose como operação tradutora ou de transcodificação, típica do design. In design define 0 caráter da semiose gráfica dos textos no contexto produtivo da linguagem, cujo objetivo é alcançar diagramas de pensamento sem 0 qual 0 conhecimento não consolida bases argumentativas de signos culturais.

\section{Referências}

BARTHES, Roland. Escrever a leitura. In: 0 rumor da língua. São Paulo: Brasiliense, 1988. p. 40-42.

BORGES, Jorge Luis. Da impossibilidade de construir a carta do império em escala um por um. In: Obras Completas. São Paulo: Globo, 1999. p.5. 
COELHO, Eduardo Prado. Introdução a um pensamento cruel: estruturas, estruturalidade e estruturalismos. In: (coord.). Estruturalismo: antologia de textos teóricos. São Paulo: Martins Fontes, 1967. p. I-LXXV.

DOSSE, François. História do estruturalismo. Bauru: EDUSC, 2007.

JAKOBSON, Roman. Lingüística e comunicação.

Tradução: Isidoro Blinkstein. São Paulo: Cultrix, 1971.

LUNENFELD, Peter. The Design Cluster. In:

LAUREL,Brenda (ed.). Design research: methods and perspectives. Cambridge: MIT Press, 2003.

MACHADO, Irene. Controvérsias sobre a cientificidade da linguagem. Líbero. Revista do Programa de Pósgraduação da Faculdade Cásper Líbero, ano XI, n. 22, p.63-74, dez. 2008.

Ecologia das extensões culturais.

In: ENCONTRO ANUAL DA ASSOCIAÇÃO

DOS PROGRAMAS DE PÓS-GRADUAÇÃO EM

COMUNICAÇÃO, 18., 2009, Belo Horizonte. Anais...

Belo Horizonte: Compós, 2009.

PIGNATARI, Décio. Informação. Linguagem.

Comunicação. São Paulo: Perspectiva, 1968. 


\section{Semiotic diagrams in} communication texts

\section{Abstract}

This article addresses the reading of communication texts as a cognitive enhancement process. For this, it starts from an assumption of need for semiotic literacy in the relational and diagrammatic structures that the media languages have introduced in the culture. It thus proposes structural reading exercises with journalistic texts in their process of representation. With this, it intends to verify how events are brought about to signify, how they become texts and what instruments languages use in order to build arguments that can be read within the structuralism of their composition.

\section{Keywords}

Structure. Diagram. Language. Argumentation. Reading. Visuality.

\section{Diagramas semióticos en textos comunicacionales}

\section{Resumen}

El presente artículo presenta una reflexión sobre la lectura de los textos de comunicación como un proceso de mejoría cognitiva en la cultura. Para ello, parte de la hipótesis de la necesidad de una alfabetización semiótica en las estructuras relacionales y diagramáticas que los lenguajes de los medios introdujeron en su cultura. Propone, así, ejercicios de lectura estructural de textos periodísticos en su proceso de representación. Pretende, por lo tanto, examinar cómo los acontecimientos significan, cómo se vuelven textos y de qué instrumentos se sirven los lenguajes para construir argumentos que puedan ser leídos en la estructuralidad de su composición.

\section{Palabras clave}

Estructura. Diagrama. Lenguaje. Argumentación. Lectura. Visualidad. 


\section{Expediente}

A revista E-Compós é a publicação científica em formato eletrônico da Associação Nacional dos Programas de Pós-Graduação em Comunicação (Compós). Lançada em 2004, tem como principal finalidade difundir a produção acadêmica de pesquisadores da área de Comunicação, inseridos em instituições do Brasil e do exterior.
E-COMPÓS I www.e-compos.org.br I E-ISSN 1808-2599

Revista da Associação Nacional dos Programas de Pós-Graduação em Comunicação. Brasília, v.12, n.3, set./dez. 2009.

A identificação das edições, a partir de 2008 passa a ser volume anual com três números.

\section{CONSELHO EDITORIAL}

Afonso Albuquerque

Universidade Federal Fluminense, Brasil

Alberto Carlos Augusto Klein

Universidade Estadual de Londrina, Brasi

Alex Fernando Teixeira Primo

Universidade Federal do Rio Grande do Sul, Brasil

Alfredo Vizeu

Universidade Federal de Pernambuco, Brasi

Ana Carolina Damboriarena Escosteguy

Pontifícia Universidade Católica do Rio Grande do Sul, Brasil

Ana Silvia Lopes Davi Médola

Universidade Estadual Paulista, Brasil

André Luiz Martins Lemos

Universidade Federal da Bahia, Brasil

Ângela Freire Prysthon

Universidade Federal de Pernambuco, Brasil

Antônio Fausto Neto

Universidade do Vale do Rio dos Sinos, Brasil

Antonio Carlos Hohlfeldt

Pontifícia Universidade Católica do Rio Grande do Sul, Brasil

Arlindo Ribeiro Machado

Universidade de São Paulo, Brasil

César Geraldo Guimarães

Universidade Federal de Minas Gerais, Brasi

Cristiane Freitas Gutfreind

Pontifícia Universidade Católica do Rio Grande do Sul, Brasil

Denilson Lopes

Universidade Federal do Rio de Janeiro, Brasil

Eduardo Peñuela Cañizal

Universidade Paulista, Brasil

Erick Felinto de Oliveira

Universidade do Estado do Rio de Janeiro, Brasil

Francisco Menezes Martins

Universidade Tuiuti do Paraná, Brasil

Gelson Santana

Universidade Anhembi/Morumbi, Brasil

Goiamérico Felício

Universidade Federal de Goiás, Brasil

Hector Ospina

Universidad de Manizales, Colômbia

Herom Vargas

Universidade Municipal de São Caetano do Sul, Brasil

leda Tucherman

Universidade Federal do Rio de Janeiro, Brasil

Itania Maria Mota Gomes

Universidade Federal da Bahia, Brasil

Janice Caiafa

Universidade Federal do Rio de Janeiro, Brasil

Jeder Silveira Janotti Junior

Universidade Federal da Bahia, Brasil

\section{João Freire Filho}

Universidade Federal do Rio de Janeiro, Brasil

John DH Downing

University of Texas at Austin, Estados Unidos

José Luiz Aidar Prado

Pontifícia Universidade Católica de São Paulo, Brasil

José Luiz Warren Jardim Gomes Braga

Universidade do Vale do Rio dos Sinos, Brasi

Juremir Machado da Silva

Pontifícia Universidade Católica do Rio Grande do Sul, Brasil

Lorraine Leu

University of Bristol, Grã-Bretanha

Luiz Claudio Martino

Universidade de Brasília, Brasil

Maria Immacolata Vassallo de Lopes

Universidade de São Paulo, Brasil

Maria Lucia Santaella

Pontifícia Universidade Católica de São Paulo, Brasil

Mauro Pereira Porto

Tulane University, Estados Unidos

Muniz Sodre de Araujo Cabral

Universidade Federal do Rio de Janeiro, Brasil

Nilda Aparecida Jacks

Universidade Federal do Rio Grande do Sul, Brasil

Paulo Roberto Gibaldi Vaz

Universidade Federal do Rio de Janeiro, Brasil

Renato Cordeiro Gomes

Pontifícia Universidade Católica do Rio de Janeiro, Brasil

Ronaldo George Helal

Universidade do Estado do Rio de Janeiro, Brasil

Rosana de Lima Soares

Universidade de São Paulo, Brasil

Rossana Reguillo

Instituto Tecnológico y de Estudios Superiores do Occidente, México

Rousiley Celi Moreira Maia

Universidade Federal de Minas Gerais, Brasil

Samuel Paiva

Universidade Federal de São Carlos, Brasil

Sebastião Albano

Universidade Federal do Rio Grande do Norte, Brasil

Sebastião Carlos de Morais Squirra

Universidade Metodista de São Paulo, Brasil

Simone Maria Andrade Pereira de Sá

Universidade Federal Fluminense, Brasi

Suzete Venturelli

Universidade de Brasília, Brasil

Valério Cruz Brittos

Universidade do Vale do Rio dos Sinos, Brasil

Veneza Mayora Ronsini

Universidade Federal de Santa Maria, Brasil

Vera Regina Veiga França

Universidade Federal de Minas Gerais, Brasi

\section{COMISSÃO EDITORIAL}

Felipe da Costa Trotta I Universidade Federal de Pernambuco, Brasil Rose Melo Rocha I Escola Superior de Propaganda e Marketing, Brasil

\section{CONSULTORES AD HOC}

Arthur Autran Franco de Sá Neto I Universidade Federal de São Carlos

Carlos Eduardo Franciscato I Universidade Federal de Sergipe

Elisa Reinhardt Piedras I Universidade Federal do Rio Grande do Sul

Elizabeth Bastos Duarte I Universidade Federal de Santa Maria

Marcia Benetti Machado I Universidade Federal do Rio Grande do Sul

Sandra Maria Lúcia Pereira Gonçalves I Universidade Federal do Rio Grande do Sul

Suzana Kilpp I Universidade do Vale do Rio dos Sinos

Tattiana Gonçalves Teixeira I Universidade Federal de Santa Catarina

Vander Casaqui I Escola Superior de Propaganda e Marketing

Vicente Gosciola I Universidade Anhembi Morumbi

Walter Teixeira Lima Junior I Fundação Cásper Líbero

REVISÃO DE TEXTO E TRADUÇÃo I Everton Cardoso

EDITORAÇ̃̃ ELETRÔNICA I Raquel Castedo
COMPóS I www.compos.org.br

Associação Nacional dos Programas de Pós-Graduação em Comunicação

Presidente

Itania Maria Mota Gomes

Universidade Federal da Bahia, Brasil

itania@ufba.br

Vice-presidente

Julio Pinto

Pontifícia Universidade Católica de Minas Gerais, Brasil

juliopinto@pucminas.br

Secretária-Geral

Ana Carolina Escosteguy

Pontifícia Universidade Católica do Rio Grande do Sul, Brasil

carolad@pucrs.br 